\title{
DIDÁTICA E TRABALHO ÉTICO NA FORMAÇÃO DOCENTE
}

\author{
MARIA MANUELA ALVES GARCIA \\ Professora do Departamento de Ensino da Faculdade de \\ Educação da Universidade Federal de Pelotas - RS \\ garciamariamanuela@gmail.com
}

\begin{abstract}
RESUMO
O trabalho discute o funcionamento de pedagogias e didáticas que se denominam críticas e progressistas no governo da conduta dos docentes críticos e intelectuais educacionais de esquerda, no Brasil das décadas finais do século passado. Apropriando-se das investigações de Michel Foucault acerca da ética e dos modos de subjetivação, explora as formas de trabalho ético e a moralidade da conduta pedagógica e docente instituídas no país pelas pedagogias críticas em algumas vertentes do discurso pedagógico brasileiro, como no pensamento de Paulo Freire, e também no pensamento de Dermeval Saviani, do início dos oitenta, dividindo as lutas do campo intelectual da educação brasileira a esse tempo. Dá ênfase a uma descrição da tecnologia pedagógica crítica posta em exercício por essas pedagogias nos cursos de formação docente em nível superior e em outros níveis de ensino, que alia a fabricação de uma moral pastoral e ascética implicada no esclarecimento das consciências e exercícios centrados em uma hermenêutica do eu que tem como característica, entre outras, a decifração de si.

DIDÁTICA - PEDAGOGIA - FORMAÇÃO DE PROFESSORES - ÉTICA
\end{abstract}

\section{ABSTRACT}

DIDACTICS AND ETHICAL WORK IN TEACHER TRAINING. This study discusses the functioning of the so-called critical and progressive pedagogical and didactic practices that guide the behavior of critical teachers and left-wing intellectuals in the area of education in Brazil in the last decades of the last century. The study appropriates Michel Foucault's investigations on ethics and modes of subjectivation, explores the forms of ethical work and the morality of pedagogical and teaching behavior inaugurated in Brazil by critical pedagogical currents in some approaches of the Brazilian pedagogical discourse, as in the thought of Paulo Freire and the one of Dermeval Saviani in the beginning of the 1980's, dividing the struggles in the intellectual pitch of Brazilian education at the time. Emphasis is given to a description of the critical pedagogical technology carried out by these pedagogical approaches in teacher education courses for elementary and higher education. It combines the construction of a pastoral and ascetic moral whose aim was to

\footnotetext{
Trabalho encomendado, apresentado em Sessão Especial do Grupo de Trabalho de Didática na 27ª Reunião Anual da Associação Nacional de Pós-Graduação em Educação - Anped -, em 22 de novembro de 2004, Caxambu, Minas Gerais.
} 
promote awareness and exercises centred in a hermeneutics of the ego, characterized, among other things, by deciphering the self.

DIDATICS - PEDAGOGY - TEACHER'S EDUCATION - ETHICS

Há anos a questão da Didática e do lugar dos saberes pedagógicos na formação e profissionalização docente tem-me chamado a atenção e impulsionado alguns de meus estudos (Garcia, 1994, 1995).

Em investigação que desenvolvi para tese de doutorado (Garcia, 2000) retomei, à luz dos estudos de Michel Foucault acerca da ética' e dos modos de subjetivação do sujeito moderno, essa questão. Tomando como objeto de análise os discursos pedagógicos críticos e seus enunciados sobre o trabalho docente crítico, problematizei essas pedagogias e suas propostas didáticas como tecnologias humanas que envolvem os sujeitos pedagógicos (professores e alunos) em trabalho ético. Nele os sujeitos são levados a se tomarem como objeto de análise para se fabricarem no interior de certos princípios e regras de conduta que pautam um jeito de ser e agir como sujeitos críticos, de princípios, conscientes e politicamente engajados. A discussão que aqui trago deriva desse trabalho. Quero defender, mediante a demonstração de um caso em particular - o das pedagogias e didáticas críticas - que a Didática, assim como outros saberes da formação profissional dos docentes, é uma tecnologia fortemente implicada na produção de modos de ser e de fazer-se professor, professora. A Didática propõe uma ética e uma ascética para os docentes, interpela os aprendizes do trabalho docente com discursos e exercícios que conformam o que Michel Foucault denominou as tecnologias de si, ou o cuidado de si, uma condição indispensável a quem se designa ou arvora ao cuidado e à educação dos outros.

A escolha dos discursos que fiz para o estudo considerou a influência que as pedagogias freireanas e a pedagogia histórico-crítica tiveram em dife-

I. $\quad$ domínio da ética e da ascética nas investigações desenvolvidas por Michel Foucault é a "história da maneira pela qual os indivíduos são chamados a se constituir como sujeitos de conduta moral: essa história será aquela dos modelos propostos para a instauração e o desenvolvimento das relações para consigo, para a reflexão sobre si, para o conhecimento, o exame, a decifração de si por si mesmo, as transformações que se procura efetuar sobre si" (Foucault, 1994, p.29). 
rentes níveis de ensino no Brasil durante as décadas de 1980 e 1990, inclusive nos currículos de formação docente em nível superior. Deixei em suspenso as diferenças e as descontinuidades entre esses discursos e seus respectivos defensores e tomei os enunciados que indicam continuidades e filiações entre eles. Do corpus discursivo que foi matéria de análise, fazem parte escritos de autores precursores dessas pedagogias como Paulo Freire e Dermeval Saviani, mas também discursos de outros autores que, situados no interior de uma ou outra dessas pedagogias, proliferaram suas ideias para o campo da Didática e das práticas escolares, como por exemplo José Carlos Libâneo e Neidson Rodrigues. Dos escritos dessas pedagogias selecionei fragmentos que têm um caráter prescritivo, que indicam uma certa moralidade da ação docente e aconselham os professores, indicando regras e procedimentos para o seu bem agir e se portar. Considerei os efeitos produtivos desses discursos sobre o ser e o agir docentes. Não foi minha preocupação empreender uma análise exaustiva e de totalidade das pedagogias estudadas, ou mesmo buscar explicar esses discursos pelas conjunturas em que emergiram. Não que eu condene esse tipo de análise, ao contrário, mas neste caso ative-me aos ditos dos discursos, tentando identificar em seus enunciados as formas de pessoalidade que instituem para os docentes bem como o funcionamento da didática crítica na produção de uma personalidade moral exemplar encarregada de guiar as consciências pelos caminhos do esclarecimento e da ação emancipada.

\section{A PEDAGOGIA E A DIDÁTICA COMO TECNOLOGIAS HUMANAS}

As pedagogias e seus métodos de ensino são conjuntos de tecnologias intelectuais ou "tecnologias humanas" que participam da normalização da conduta e da alma humana. São tecnologias nas quais estão implicadas formas de poder que produzem "coisas", formas de ver, pensar, saber, viver, ensinar, aprender. Tecnologias que, como "conjuntos estruturados de práticas governadas racionalmente por objetivos e metas mais ou menos conscientes" (Rose, 1996, p.26), ou como "a articulação de certas técnicas e de certos tipos de discurso acerca do sujeito" (Foucault, s.d., p.206), tornam os seres humanos objetos de sua ação e certos tipos ou estilos de seres humanos como matéria a ser fabricada. As pedagogias como conjuntos de tecnologias humanas são aquilo que Foucault (1987a) chamou disciplinas, focos de poder-saber que pelo 
exame constituem o indivíduo como efeito e objeto do poder, como efeito e objeto do saber, assegurando uma distribuição "infinitesimal das relações de poder", de modo a ordenar a "multiplicidade humana" e a maximizar a utilidade de suas forças vitais e sociais. A Pedagogia e a Didática desenvolvem-se ao longo da Modernidade como instâncias de governo da conduta humana em direção a uma especificação e a uma individuação crescente da população de aprendizes, adotando para governo o sentido que Foucault (1995) atribuiu ao termo: uma ação sobre ações possíveis, uma interferência organizada de modo a possibilitar a criação de um campo de possibilidades para a ação dos outros.

Dessa forma, a pedagogia e a didática são tecnologias humanas que implicam trabalho ético dos indivíduos sobre si próprios. Propõem aos indivíduos um conjunto de regras facultativas que configuram certo estilo e certa forma de existência e um conjunto de exercícios que tomam como objeto de fabricação a matéria e a alma humana enquanto sujeitos de conduta moral. A Pedagogia e a Didática são formas de poder-saber, discursos disciplinares que exercem formas de governo dos indivíduos e das populações à medida que os transformam em sujeitos e assujeitados de certo tipo. As pedagogias tratam de conduzir e determinar a conduta dos indivíduos e dos grupos que são alvos de sua ações e programas. Exercem uma forma de governo da conduta humana que implica uma relação de forças entre sujeitos "livres" e uma relação de forças sobre si próprio. Uma relação de forças entendida como "jogos estratégicos" que tentam agir sobre as possibilidades de ação dos outros e de si, sejam essas ações eventuais, atuais, presentes ou futuras.

Apesar da estranheza que essa ideia costuma causar, o cuidado é imanente à Pedagogia: o ensinar e o aprender envolve o cuidado dos outros e de si. A autoridade de quem ensina assenta-se em dupla obrigação: o governo da conduta alheia exige o governo de si. A tarefa da pedagogia é eminentemente moral. $\bigcirc$ trabalho sobre as consciências e os instintos humanos nas democracias liberais de nosso tempo exige o autogoverno e a autorregulação daqueles e daquelas que o exercem. Laica ou religiosa, a conduta moral tem que ser fabricada. Trabalho de governo dos homens e da população exercido por uma variedade cada vez maior de instituições e discursos na Modernidade. Trabalho de governo que exige um processo de individuação e escrutínio crescente da população, tarefa para a qual são demandados saberes e exercícios especializados. Entender a Didática e a Pedagogia nessa perspectiva é a recuperação do que há de material nos proces- 
sos de formação humana. A compreensão de que a humanidade, afinal, é uma fabricação que exige tempo, cuidado, dispositivos e tecnologias. A Pedagogia e a Didática estão centralmente implicadas nessa fabricação.

\section{O REGIME DO EU DO INTELECTUAL E/OU DOCENTE CRÍTICO}

Por "regime do eu" do docente crítico, termo tomado de empréstimo a Rose (1 996), faço referência a um conjunto de coordenadas temporais e geográficas, a determinada forma de pessoalidade, ou subjetividade, instituída pelas pedagogias críticas estudadas para os docentes. São atitudes, princípios para a ação, modos de operar que constituem uma normatividade ou um conjunto de ideais regulativos que caracterizam a maneira de agir e se conduzir do docente crítico. As pedagogias críticas propõem formas particulares de experiência aos docentes: experiência de si, experiência com os outros na relação pedagógica, experiência com as coisas do mundo.

A docência nos discursos pedagógicos críticos é o exercício de uma função que tem por tarefa a produção do sujeito de consciência e do "bem" agir (de modo crítico e emancipado). Em nome dessa função esclarecedora, humanizadora e salvadora, essas pedagogias instituem para os docentes a moral de um asceta aliada a convicções políticas profundas. Docentes e outros guias e intelectuais pedagógicos são posicionados como intelectuais universais e de esquerda, cuja personalidade moral exemplar está baseada na autorreflexão e na autodeterminação e num certo fundamentalismo intelectual de esquerda.

Para o exercício dessa tarefa conscientizadora professores e intelectuais são interpelados com uma forma de pessoalidade que deve ter como características a capacidade de interpretar e traduzir as necessidades e aspirações dos que são objetos dos programas educativos, oferecendo-lhes as possibilidades programáticas e políticas que os podem alçar de sua miséria cultural e política; ser um sujeito de princípios e condutas exemplares, a fim de educar pela retidão e pela coerência de sua conduta e crenças; ter atitudes constantes de autorreflexão e autoexame, vigiando e zelando pelos próprios pensamentos e por sua conduta para não se desviar dos princípios que devem pautar a relação pedagógica e seus objetivos emancipadores.

A tarefa pedagógica do intelectual educacional ou do professor crítico é "orientar as consciências para a ação". Deve contribuir para que, pelo questio- 
namento da conduta humana, "os homens possam reencontrar a si mesmos, à sua conformação histórica e à sua capacidade de agir. Sem tais questionamentos e posições é impossível compreender a situação e transformá-la" (Rodrigues, 1987, p. I5-16). Tarefa para intelectuais universais e "de esquerda" que, mesmo situados em lugares de trabalho nos quais estão submetidos a controles e relações de ordem institucional, lutam contra o poder em nome da verdade, da cientificidade, da objetividade, da justiça e da razão histórica.

O docente e intelectual educacional crítico deve ser o portador de valores universais como a razão, a verdade, a justiça, a liberdade e a emancipação. Sua posição tem a ver com certas relações de saber e poder. Em nome da verdade e de outros valores universais, exerce um tipo de poder produtivo que normaliza as condutas e multiplica a força dos indivíduos em relação a uma ordem de objetivos e metas particulares. Tem autoridade de guiar as consciências, de revelar os seus erros e ilusões. Tem o poder de reformar, de guiar e curar os indivíduos. O sujeito docente crítico realiza o esclarecimento das consciências, acompanhando suas performances e evoluções rumo a um maior discernimento e engajamento. Essa é a sua função: exercer uma forma de pastorado da consciência crítica e engajada, acompanhando com dedicação e atenção cada indivíduo em particular e todos em rumo a uma existência racional e moral superior.

Intelectuais educacionais de esquerda, ou docentes críticos, por suas relações com o saber e a verdade, assumem a função de guias, intérpretes e representantes dos interesses dos seres humanos e da humanidade. Profetizam o futuro, anunciam a verdade e criam modelos de virtude, de moralidade e bom comportamento. Ao assumirem esse papel, os "outros" ou as "outras" da relação pedagógica, os alunos e as alunas, ou os grupos populares e "oprimidos", alvos dos programas de educação crítica, são constituídos como necessitando de algo, como carentes de saber, de iniciativa e de consciência política. Intelectuais e professores investem-se do poder de representar o outro, de dar a conhecê-lo e a sua realidade, e se investem do poder de convertê-lo em uma entidade superior que afastou de si o erro, a mistificação e os efeitos danosos da dominação econômica e política.

Os saberes que intelectuais e docentes professam funcionam como sistemas de divisão e exclusão de outros discursos ditos "falsos", "ingênuos", "alienados", "fatalistas", "senso comum" etc. As palavras e os discursos daqueles 
que são alvo das ações pedagógicas críticas são acolhidos para, afinal de contas, serem substituídos por outros mais verdadeiros e precisos. Os discursos que os professores e as professoras críticas professam estão animados por uma vontade de verdade que tem um suporte institucional (a escola, os currículos, a ciência, as disciplinas, os institutos de pesquisa, as sociedades profissionais e científicas etc.). Exercem um poder de constrição sobre outros discursos que ordena a multiplicidade, a heterogeneidade, a descontinuidade e conjura o perigo, a violência, o aleatório e a desordem do que é dito por aqueles que são tidos como carentes de razão, de saber, de equilíbrio, de independência emocional etc. Os discursos pedagógicos instituem políticas de verdade das quais participam os docentes críticos e outros intelectuais educacionais. Esses discursos afirmam a supremacia da razão científica e a universalidade de valores como igualdade, justiça etc.

"Não se é educador como se é operário de uma fábrica de móveis" declara Rodrigues ( 1987, p.65). $\bigcirc$ "educador consciente" luta para que a escola seja competente em possibilitar aos trabalhadores e seus filhos as condições intelectuais e sociais para que possam construir "um espírito de solidariedade e autodesenvolvimento" ( p.76). Nessa tarefa, o professor e a professora devem ter uma conduta exemplar, porque "a imitação é o primeiro e mais poderoso veículo para a formação da consciência do educando". Assim, "devemos cuidar para que nossos comportamentos sejam sobretudo imitáveis por eles" ( p.85).

Professores e intelectuais educacionais críticos precisam ter um comportamento ético cuja virtude está nos princípios que defendem e no exercício da autorreflexão e da autodeterminação, sendo exemplos morais a serem seguidos por aqueles que estão sob seus cuidados. O projeto de formação humana que o intelectual educacional crítico encarna tem algo do "homem cultivado", de uma personalidade prestigiosa, que exerce uma função carismática, destacandose por atributos tais como a vocação, a paixão e o compromisso moral com a universalização de valores como a justiça, a humanização e a verdade. Se as condições materiais da profissão docente se assemelham às de funcionário civil, sua formação moral é decididamente pastoral.

A vocação refere-se a uma ocupação que exige paixão e compromisso moral de seus praticantes. É um chamado ou missão. O mestre, como o médico e o sacerdote, libera, cura e salva. A proximidade entre a educação, a pedagogia e a medicina é muito antiga. Entre os gregos, as academias eram "dispensários 
da alma". Para os ilustrados, a escola estava ligada à saúde e à enfermidade das almas e dos corpos, ao normal e ao patológico, engajando-se no trabalho de moralização e higienização da população. A educação e a pedagogia modernas não deixam de ser formas de cuidado e de ser um "serviço da consciência" e da autoconsciência.

Os sujeitos docentes críticos são sujeitos de suas próprias ações, que se governam a si próprios e se autorregulam como sujeitos de consciência e de princípios. Comprometimento político e competência técnica são requisitos dos educadores críticos e progressistas, porém diferentemente enfatizados pelos discursos. Alguns discursos instituem que o mais importante mesmo na função docente são os compromissos éticos expressos na defesa de determinados pactos e princípios como a democracia, a igualdade, a liberdade responsável, a defesa dos oprimidos e dos explorados.

Já para outros discursos, o compromisso político e ético do educador progressista fundamenta-se na competência técnica, no "saber fazer", na capacidade de possibilitar o acesso dos alunos à tradição cultural e científica. $\bigcirc$ dever do educador consciente é lutar por uma escola competente que possibilite aos filhos dos trabalhadores as condições intelectuais e sociais para a construção de um "espírito de solidariedade e de autodesenvolvimento". A humanização e o esclarecimento são o cerne de sua tarefa pastoral, e dependem do "progresso intelectual" que se consiga alcançar.

A produção do sujeito docente como um sujeito que pauta sua conduta por princípios, comprometido com a justiça, com o esclarecimento e a emancipação, com a humanização e o pensamento crítico, é o resultado de uma ocupação constante e dedicada do sujeito consigo mesmo e com o ato educativo. "Ninguém é comprometido, politicamente, de uma vez por todas. O compromisso é como um ato de amor, que tem de se renovar diariamente" (Rodrigues, 1989, p.66). O compromisso depende de trabalho ético do indivíduo sobre si próprio na medida em que constitui os outros como sujeitos de certo tipo por meio de determinadas tecnologias.

\section{A TECNOLOGIA PEDAGÓGICA CRÍTICA NA FORMAÇÃO DOCENTE}

As Pedagogias críticas implementam uma tecnologia pedagógica, na formação e no treinamento docente, que privilegia as práticas de si e as práticas 
exemplares, introduzindo aprendizes do magistério e do trabalho pedagógico nas artes da "boa" consciência e da autodeterminação, de modo a produzi-los como sujeitos de princípios e engajados.

Os discursos pedagógicos críticos exortam professores e professoras a constantemente e exaustivamente refletirem e examinarem os seus pensamentos e os princípios que pautam o trabalho didático e pedagógico que desenvolvem no cotidiano de suas tarefas: "para que ensinar?", "em favor de quem?", "que tipo de homem formar?", "para que tipo de sociedade?", "de que lado estou?" etc. Questões de princípio que devem determinar o conteúdo e as formas críticas de ensinar e aprender desenvolvidas nas salas de aula com os sujeitos aprendizes. Princípios que devem ser objeto de constante zelo e vigilância pela autorreflexão, sob pena do trabalho docente ter efeitos incontroláveis e contrários aos desejados.

As práticas de si e o cuidado consigo são aspectos fundamentais daqueles que exercem uma função pastoral. "O sábio necessita manter suas virtudes em alerta” (Foucault, 1985, p.59). Ao estimular os outros ao trabalho ético, ele próprio é estimulado, estabelecendo com aqueles que estão sob seus cuidados um jogo de trocas e obrigações recíprocas. Essa é a característica central do cuidado de si. Não é um exercício solitário, ao contrário do que se pode pensar apressadamente, mas está implicado em inúmeras relações e práticas sociais, como é o caso da educação.

Cuidar de sua própria conduta, vigiar seus pensamentos, zelar pela coerência entre o que é dito e o que é feito, é tarefa sem tréguas de educadores e intelectuais educacionais críticos. Os educadores críticos têm de cultivar as artes da autorreflexão e da autodeterminação em si próprios para que possam nelas iniciar seus estudantes. Como Sócrates já dizia, ao ensinar os cidadãos a ocuparem-se de si mesmos se lhes ensina também a ocuparem-se da própria cidade (Foucault, 1997, p. I19-120).

A direção da consciência nos currículos críticos de formação docente implica um tempo "povoado" de exercícios: autorreflexões em torno de si mesmo e de questões problemas sobre os objetos e as finalidades da educação, do ensino, do tipo de personalidade e de sociedade que se quer formar. Implica também a memorização e a rememoração de regras de conduta e dos princípios da relação pedagógica crítica e democrática, mediante leituras, trabalhos escritos e investigações da prática. Requer, ainda, o autoconhecimento, 
tomando-se a si próprio, ao seu pensamento e à sua prática, como objetos de constante zelo, vigilância e autocorreção, seja em exercícios solitários ou sob a direção de outrem. A figura do professor autorreflexivo é o ideal da formação de professores de uma variedade imensa de posições e práticas de formação, na literatura sobre currículo e formação docente.

As práticas autorreflexivas envolvem toda uma série de tecnologias intelectuais, orais e escritas, que vão desde os relatos orais e os "diários" de classe do professor, às fichas de observação e autoavaliação, aos relatórios de observações da prática e de estágios etc. Formas de mostrar-se ao outro, de dar-se a ver a olhares e ouvidos atentos, de objetivar-se a si próprio, possibilitando a correção e a autocorreção. A escrita é um elemento do autoconhecimento e da autocorreção (do "treino de si"); opera a transformação da verdade em ethos; estabelece princípios de conduta racional, podendo ser retomada para meditações posteriores. A escrita é um "elemento indispensável da vida ascética" (Foucault, 1992). Permite o exercício do pensamento sobre o próprio pensamento e a subjetivação dos discursos "verdadeiros".

Reconhecer-se como seres de certo tipo (democráticos, conscientes, solidários, compromissados etc.), estetizar a própria conduta para transformarse no ideal do professor crítico (diretivo, humilde, amoroso, esperançoso, paciente etc.), vigiar-se (ser coerente, permanecer alerta contra os perigos do autoritarismo e da alienação etc.) são práticas de si que os discursos pedagógicos críticos instituem para docentes e intelectuais educacionais críticos.

Desse virtuosismo autorreflexivo emana a autoridade moral que solicita a alunos e alunas tomarem suas próprias condutas como objeto de reflexão e responsabilidade. Não é por acaso que nos relatos e exercícios autobiográficos que se desenvolvem nas salas de aula críticas a confissão, muitas vezes, inicia-se pelo professor, de modo a estimular o desapego dos demais em relação a suas próprias experiências. $\bigcirc$ testemunho do professor ou da professora conta a experiência de uma renúncia e de uma conversão bem-sucedidas, enquanto o testemunho de si a ser feito por aqueles que praticam a confissão na condição de aprendizes tem o objetivo de deixar para trás uma experiência permeada pelos enganos, pelos mitos e pelas sombras da ignorância. O testemunho de si do professor é ao mesmo tempo, um exemplo a ser seguido e a promessa de que o autossacrifício da confissão, no final das contas, terá suas recompensas. 
Considerando o virtuosismo reflexivo do educador crítico e progressista, torna-se concebível uma didática nos cursos de formação docente que tem seu foco nas "vivências", nas experiências e nas "memórias" de alunos-mestres, ou talvez futuros mestres, aprendizes do trabalho docente. A incitação à autorreflexão e ao autoconhecimento ocorre por meio do pensamento de si, do exame de consciência e da exposição do eu. São exemplos desses procedimentos a utilização de "histórias de vida"; os exercícios orais e escritos de memória escolar ou outros relatos de aspectos autobiográficos que obedecem a certos critérios e normas; os relatórios avaliativos das experiências de ensino que os alunos vivenciam como parte dos currículos de formação profissional. Todas essas, e outras mais, são oportunidades de aprendizagem de uma certa linguagem para se ver, narrar, pensar, julgar e corrigir como um sujeito portador de certos valores e atitudes. Esses exercícios e práticas pedagógicas da formação docente são formas de objetivação de si e de autodeterminação da conduta dos indivíduos que deles participam.

A pedagogia crítica voltada para a produção de docentes e intelectuais educacionais radicais e progressistas é uma pedagogia centrada nas práticas de si e na investigação da prática, especialmente das "exemplares" e "boas" práticas. Caracteriza-se por ser um trabalho centrado em uma hermenêutica de si ao lado do fornecimento de modelos de abnegação e compromisso que têm êxito, apesar das circunstâncias desastrosas do sistema escolar e dos contextos desfavoráveis. É evidente o interesse da Didática por formas de investigação como a pesquisa-participante e os trabalhos etnográficos que têm como foco as "boas" práticas e as experiências exitosas, os professores e as professoras que "dão certo". Há uma profusa literatura educacional que circula nas salas de aula críticas dos cursos de capacitação docente, cujos títulos demonstram esse tipo de preocupação. Essas investigações, o uso da biografia e da autobiografia críticas nas salas de aula, são modos de produção de um certo estilo de percepção dos indivíduos, por meio do qual certas entidades e eventos são visualizados de acordo com imagens particulares e padrões específicos. Ao selecionarmos, ou ao selecionarem para nós, os modos de nos narrarmos, estamos também implicados em uma autoinvenção, ou fabricação de nossa própria subjetividade. 


\section{NARRAR-SE, CONVERTER-SE E LIBERTAR-SE}

Os discursos pedagógicos críticos recolocam, em seus próprios termos, as ideias cristãs da redenção e da conversão, cujas raízes, dizem Lerena ( 1983 ) e Corazza ( 1 998), estão em uma antropologia socrático-platônica. Pretendem operar um movimento profundo na consciência dos indivíduos, fazendo com que mudem de posição e se voltem para uma direção completamente nova, movimento em que os seres humanos reencontram-se com sua natureza mais profunda e essencial e seu destino histórico: a plenitude de sua humanidade e de sua racionalidade moral como indivíduo e coletividade. Nesse processo, os seres humanos corrigem-se, curam-se, convertem-se, libertam-se e renascem por um contínuo processo de busca, de confrontação, de formação e transformação de si e do mundo.

Para tornar-se mais humano, para transformar-se em um sujeito racional e moral, é-se obrigado a dizer a verdade acerca de si próprio para imediatamente a ela renunciar em nome de uma verdade mais absoluta e essencial - a verdade da razão e de sua condição e situação de classe social -, e em nome da produção de uma nova forma de subjetividade: uma subjetividade esclarecida, humanizada e politicamente engajada. Para os sujeitos pedagógicos não se tornarem vítimas de sua apreensão "ingênua", desprevenida ou "deturpada" da realidade é preciso que submetam os próprios pensamentos a um constante trabalho de hermenêutica e interpretação, que se enfrentem com a própria realidade, a fim de descobrir uma verdade que se encontra oculta pela ideologia, fruto da dominação e da opressão de classe. Os métodos das pedagogias críticas, ao levarem os indivíduos a formas de confissão e de relatos do eu, os impelem a realizarem uma trajetória que vai da autocrítica à transformação. percurso inicia-se em um relato no qual os indivíduos dizem como são ou como eram e termina, geralmente, por outro relato em que os indivíduos reconhecem que algo de fundamental aconteceu no trajeto e em suas vidas, modificando profundamente a visão e modo de ser e agir no mundo.

Foucault (s.d., 1987) estudou de modo detalhado² a longa tradição desses procedimentos e suas transformações na cultura ocidental. Presentes já no

2. Especialmente em História da sexualidade e em seus cursos e conferências do período 1980-1982. 
Mundo Antigo, a confissão e o exame de consciência sempre foram "práticas de si" que estiveram orientadas para a produção da verdade acerca de si mesmo. Mas é somente com o cristianismo que o exame de consciência e a confissão aparecem no interior de uma hermenêutica do eu que impõe a obrigação à verdade, que toma o processo de pensamento como objeto de uma análise interpretativa, a fim de se descobrir uma realidade dissimulada no interior dos próprios pensamentos ou o poder insidioso que se infiltra sorrateiramente no interior de si.

Foi essa hermenêutica cristã do eu que deu origem ao conceito ocidental de sujeito, a qual se caracteriza por um processo de autodecifração, que busca uma verdade oculta no interior do sujeito, e na qual a conversão é entendida como um caminho de obstáculos que exige renúncia e ruptura com uma subjetividade ou um modo de ser anterior. Um caminho ao final do qual o indivíduo renasce profundamente modificado em relação a si próprio. A conversão exige a automortificação e o autossacrifício como condições de purificação e salvação. Essa é a herança do cristianismo que foi secularizada e mundanizada pelo exercício do poder disciplinar e pastoral que se ampliou consideravelmente por muitas e diferentes práticas e instituições a partir do século XVII e, especialmente, nos séculos XVIII e XIX. E ainda hoje, essa é uma herança que se renova em inúmeras práticas e saberes que tomam o homem e sua existência como objeto e efeito do poder e do saber, entre elas a pedagogia e os saberes pedagógicos críticos.

Em diversos momentos dos métodos críticos de ensino, os sujeitos são levados a confessar-se e a fazer narrativas sobre si, a serviço de uma hermenêutica do eu que, em nome da produção e da emergência de uma nova subjetividade, esclarecida e emancipada, submete os indivíduos a um trabalho de autointerpretação e de autoanálise na presença de um mestre (e de outros parceiros), para que "descubram" os erros e as insuficiências de suas vidas, os aspectos enganadores e mistificadores de suas formas de raciocínio e existência, e fabriquem uma subjetividade mais essencial e verdadeira.

A obrigação à verdade por meio da confissão aparece nos discursos das pedagogias críticas de múltiplas formas. Os sujeitos pedagógicos são introduzidos nas artes da autorreflexão pelas "microtécnicas" da consciência que constituem a disciplina espiritual que herdamos do cristianismo. Os relatos autobiográficos fazem parte dessa tecnologia da consciência do sujeito mo- 
derno e contemporâneo. A incitação do discurso dirigido aos docentes para que pratiquem, solitariamente ou com seus pares, a autorreflexão e o exame de si mesmo é outra forma de obrigação à verdade.

Quando se dirigem a professores e professoras é comum a utilização de um tipo de discurso que toma a forma de uma autorreflexão ou autoconfissão, de um diálogo consigo mesmo na primeira pessoa do singular, no qual o sujeito levanta um problema e ele mesmo imediatamente responde e soluciona. Tratase de um discurso interior, em que o outro, que não é "outro" senão "ele" mesmo, responde, aconselha, repassa princípios e normas de conduta, sugere soluções, desempenhando o duplo papel de conselheiro ou guia e aquele que é guiado, conduzido (Freire, Shor, 1987, p.69-70).

Os sujeitos são incitados a converter-se em nome de uma subjetividade mais esclarecida e engajada e em nome de uma vida e de uma sociedade moralizadas. Os indivíduos são incitados a levarem uma vida racional e ativa, de princípios comprometidos com a construção de uma sociedade mais justa, igualitária e emancipada. Para tanto, é preciso cuidar de si mesmo e preocuparse por si mesmo com rigor e afinco. As tecnologias que permitem fazer esse trabalho ético foram uma invenção do mundo antigo grego, helenístico e romano (Foucault, 1990, 1992, s.d.).

Essas tecnologias (especialmente a confissão e o exame de consciência), posteriormente, foram transferidas e reaclimatadas com outros conteúdos e objetivos no interior da disciplina espiritual cristã, assumindo formas muito diversas das que apresentavam na Antiguidade clássica. Na espiritualidade cristã, o cuidado de si por meio daquelas técnicas passa pela renúncia a si mesmo em nome do renascimento e da salvação no outro mundo. Modernamente, o cuidado de si e sua tecnologia ascética foi integrado, tanto em contextos que buscam adaptar os indivíduos e curar os males do corpo e da alma, quanto em contextos nos quais predomina uma ética de não-egoísmo e de obrigação para com os outros. Entendendo por outros a coletividade, a classe social, os oprimidos, os trabalhadores etc.

Foi a ética cristã a responsável por aliar dois aspectos éticos que parecem ser opostos: o rigor moral da preocupação por si mesmo que toma o autoconhecimento como condição de salvação e a moral de não-egoísmo e preocupação e cuidado dos outros. A salvação e a conversão cristãs implicam paradoxalmente o autoconhecimento e a renúncia a si em nome do renasci- 
mento e do ingresso na existência plena do mundo espiritual (Foucault, 1987). O resultado de uma combinação secularizada desses princípios nos discursos que aqui estudo é uma ética de autovigilância e de autonegação em nome da salvação de si próprio e da sociedade, pela produção de uma forma de subjetividade superior, mais esclarecida e engajada, e da transformação de uma sociedade injusta e desigual numa existência social mais justa e igualitária.

Os saberes da tradição cultural e da ciência, subjetivados por métodos de ensino, e o exercício da conscientização pelo diálogo, são os instrumentos da tecnologia pedagógica crítica que possibilitam o movimento de conversão dos indivíduos. De um modo ou de outro, o que se pretende é atuar sobre os indivíduos a fim de modificá-los, redimi-los de suas misérias e de sua natureza decaída (a ignorância, a desumanização, a ingenuidade, a passividade, a alienação, o conformismo etc.), transformando-os e transfigurando-os em alguém distinto e superior.

Nos casos das pedagogias críticas, o que se deseja maximizar é o papel da razão e da agência humana na história pela produção de um consenso em torno de uma determinada forma de representação das relações sociais, da história e seu desenvolvimento, e pelo engajamento em lutas de cunho político que visem a conquista do aparelho de Estado. Nessa direção, os métodos didáticos críticos são tecnologias humanas (e intelectuais, também) que visam modificar o comportamento de individualidades (singulares ou coletivas, como a classe social), de modo a se tornarem críticos, esclarecidos, com princípios, conscientes, ativos e engajados, em síntese, individualidades moralizadas.

As pedagogias críticas são tecnologias que funcionam mediante um poder invisível, discreto, que não tem seu princípio em uma pessoa ou instância em particular, mesmo estabelecendo uma hierarquia de autoridade. A relação pedagógica crítica é uma relação de forças do tipo pastoral que, agindo de modo calculado e racional, e em nome da verdade e da emancipação, pretende modelar a consciência e a conduta dos sujeitos sobre os quais atua.

A observação e o exame exaustivos da experiência de vida dos indivíduos e das populações que são alvos dos programas de educação crítica e libertadora produzem um domínio de saberes sobre os seus modos de pensamento e de vida. Saberes sujeitos que, ao serem normalizados no processo de sua organização e devolução, irão conferir uma identidade mais "verdadeira" a essas individualidades, reforçando sua sujeição no mesmo processo de libertação e 
emancipação. Pela observação e pelo exame, se determina a cada um o seu nível de consciência, suas debilidades e virtudes, por meio de um poder que identifica as "verdades" das individualidades analisadas e suas insuficiências, para Ihes prescrever os remédios possíveis, a fim de que alcancem uma identidade superior e mais "verdadeira".

Poder e saber têm uma relação de circularidade que Foucault caracterizou como típica do poder disciplinar. Poder e saber, sendo distintos, estão diretamente implicados, e não nos termos de uma "contaminação" do saber pelo poder, ou nos termos da utilidade do saber para o poder. $O$ poder produz saber, as relações de poder supõem e implicam a constituição de campos de objetos e saberes, e o saber supõe e constitui ao mesmo tempo relações de poder. Mas o modo pelo qual essas relações são problematizadas, do ponto de vista dos discursos educacionais críticos, compartilha uma tradição "que deixa imaginar que só pode haver saber onde as relações de poder estão suspensas e que o saber só pode desenvolver-se fora de suas injunções, suas exigências e seus interesses". Ou que o poder enlouquece e que "em compensação a renúncia ao poder é uma das condições para que se possa tornar-se sábio" (Foucault, 1987, p.29-30).

Humanização e disciplina, esclarecimento e sujeição, liberdade e constrangimento são as duas faces do mesmo processo de poder pastoral-disciplinar. Uma forma de poder que realiza uma economia do detalhe e opera através de um olhar esmiuçante que, acompanhado de uma série de técnicas de notação e registro, funciona ao mesmo tempo como mecanismo de individualização e técnica de adestramento e normalização dos indivíduos e das populações sobre as quais age.

Retirar-se do anonimato das vidas e das experiências comuns e dele ser retirado por olhares compreensivos e vigilantes; expor os seus corriqueiros pensamentos e modos de vida a olhares interessados; ocupar um lugar nos "círculos de cultura" ou em outros arranjos e distribuições de corpos nos espaços das salas de aula democráticas e participativas; elaborar e escrever narrativas acerca de si mesmo e de seu cotidiano confrontando-as com as de outros; avaliar-se a si próprio e a outros segundo critérios deliberados coletivamente; participar ativamente do grupo tornando-se um sujeito corresponsável e comprometido são as formas de poder que disciplinam as almas e as condutas dos aprendizes das salas de aula críticas. 
Combinar autoridade e liberdade, limites e autonomia, cuidar de todos e de cada um em particular, envolver-se com os estilos de vida de seus alunos, com seus problemas e dificuldades, orientando-os na busca da verdade; dedicar-se abnegada e amorosamente a sua tarefa de guia das consciências exigindo o esforço dos alunos e sua mobilização para uma participação ativa na sala de aula e na sociedade; fazer com que seus exemplos e palavras tenham impressões e efeitos formativos duradouros sobre as consciências pela demonstração de compromisso, de competência e de qualificação no exercício de sua tarefa; vigiar incansavelmente o progresso de todos e de cada um em direção ao esclarecimento e ao engajamento; renovar diariamente seus compromissos com o progresso e a salvação de seus estudantes e da sociedade são as bases e os fundamentos da tarefa do educador crítico ou da educadora crítica.

\section{REFERÊNCIAS BIBLIOGRÁFICAS}

CORAZZA, S. M. História da infantilidade: a-vida-a morte e mais-valia de uma infância sem fim. Tese (dout.) Faculdade de Educação, Universidade Federal do Rio Grande do Sul. Porto Alegre, 1998.

FOUCAULT, M. A escrita de si. In: O que é um autor? Lisboa: Vega, Passagens, 1992. p. I29-160.

. Hermeneutica del sujeto. Madrid: La Piqueta, 1987.

A Hermenêutica do sujeito (1981 - 1982). In: Resumo dos cursos do Collège de France (1970-1982). Rio de Janeiro: Zahar, 1997. p. I I 8- 13.

História da sexualidade, 3: o cuidado de si. 5. ed. Rio de Janeiro: Graal, 1985. História da sexualidade, 2: o uso dos prazeres. 7. ed. Rio de Janeiro: Graal, 1994.

O Sujeito e o poder. In: RABINOW, P.; DREYFUS, H. Uma trajetória filosófica: para além do estruturalismo e da hermenêutica. Rio de Janeiro: Forense Universitária, 1995. p.231-249.

Tecnologías del yo. In: Tecnologías del yo y otros textos afines. Barcelona: Paidós Ibérica; Universidad Autónoma de Barcelona, 1990. p.45-94.

Verdade e subjetividade (Howison Lectures). Revista de Comunicação e Linguagem, Lisboa, n. 19, p.203-223, s.d. (Conferências proferidas em Berkeley, em 20 e 21 de outubro de 1980) 
Vigiar e punir. 5. ed. Rio de Janeiro: Vozes, $1987 \mathrm{a}$.

FREIRE, P.; SHOR, I. Medo e ousadia; o cotidiano do professor. 2. ed. Rio de Janeiro: Paz e Terra, 1987.

GARCIA, M. M. A. O Campo da didática no ensino superior: um enfoque sócio-histórico. Educação \& Realidade,Porto Alergre, v.20, n. I, p.73-91, 1995. A Didática no ensino superior. Campinas: Papirus, 1994. A Função pastoral-disciplinar das pedagogias críticas. Tese (dout.) Faculdade de Educação, Universidade Federal do Rio Grande do Sul, Porto Alegre, 2000. Pedagogias críticas e subjetivação: uma perspectiva foucaultiana. Petrópolis:

Vozes, 2002.

LERENA, C. A. Reprimir e liberar: crítica sociológica de la educación y de la cultura contemporáneas. Madrid: Akal, 1983.

RODRIGUES, N. Da mistificação da escola à escola necessária. 3. ed. São Paulo: Cortez, 1989. Lições do príncipe e outras lições: o intelectual, a política, a educação. II. ed. São Paulo: Cortez; Autores Associados, 1987.

ROSE, N. How should one do the history of the self? In: ROSE, N. (org.) Inventing our selves; psychology, power, and personhood. Cambridge: Cambridge University Press, 1996. p.22-40.

Recebido em: janeiro 2006

Aprovado para publicação em: abril 2007 